DOI: 10.5604/01.3001.0011.6005

\title{
METHODS OF PRODUCING APODIZED FIBER BRAGG GRATINGS AND EXAMPLES OF THEIR APPLICATIONS
}

\author{
Lukasz Zychowicz, Jacek Klimek, Piotr Kisała \\ Lublin University of Technology, Institute of Electronics and Information Technology
}

Abstract. The paper presents the principle of operation, the structure, applications and methods of producing uniform, chirped and blazed fiber Bragg gratings as well as long period gratings. Finally, several selected methods used to make apodized gratings are listed and described.

Keywords: apodized fiber Bragg grating, uniform Bragg grating, chirped Bragg grating, long-period grating, blazed Bragg grating

\section{METODY WYTWARZANIA I ZASTOSOWANIE APODYZOWANYCH SIATEK BRAGGA}

Streszczenie. W artykule omówiono zasadę działania, budowę $i$ zastosowania apodyzowanych siatek Bragga: równomiernych, o zmiennym okresie, długookresowych i skośnych oraz wptyw apodyzacji na te siatki. Na koniec wymieniono i opisano kilka wybranych metod stosowanych do wytworzenia apodyzowanych siatek.

Słowa kluczowe: apodyzowane siatki Bragga, równomierna siatka Bragga, siatka Bragga o zmiennym okresie, siatka długookresowa, skośna siatka Bragga

\section{Introduction}

At the end of the 1970s, it was noticed that the creation of periodic structures in glass fibers can significantly expand the field of applications of fiber optics [10]. In the 1980s, the first proposals for the use of Bragg gratings began to appear [19], and it was only in the 1990s that their manufacturing technology was sufficiently advanced to apply the gratings practically $[6,21]$. The first publications regarding the apodized gratings were published in 1995-1996 [26, 29]. Since then, these gratings have been intensively researched and developed (including uniform, chirped and blazed gratings, and long-period gratings, discussed in detail in the further part of the paper), as evidenced by the large number of published articles, that are mentioned in the following paragraphs.

\section{Principle of operation of the Bragg gratings}

The optical fiber Bragg gratings feature periodic changes in the refractive index of the optical fiber core. They are produced by removing the coating of the optical fiber, resulting in the jacket being exposed. On the fiber prepared in this way, the fringes are inscribed with laser light at appropriate distances from each other. The grating acts as a selective mirror - it reflects the light of a specific wavelength (the so called Bragg wavelength), while the light with other wavelengths (which do not meet the Bragg condition, defined by equation 1 - the case of the uniform grating) passes practically without losses.

$$
\lambda_{B}=2 n_{e f f} \cdot \Lambda,
$$

where $n_{\text {eff }}$ is the effective refractive index of the optical fiber core, and $\Lambda$ is the period of the grating.

\section{Apodization profiles}

It was noted that the functionality of the optical fiber Bragg gratings can be significantly improved by using apodization. There is a true apodization and a non-true apodization. Apodization is a technique of eliminating the unfavorable features of the spectrum - the true apodization can effectively eliminated side-lobes in the reflected spectrum [7]. In addition, it was noted improvement of a group delay (GD) responses of the apodized chirped FBG [31] and a shaping of efficiency of the Bragg wavelength harmonics reflection (i.e. reflections at wavelength that satisfy the higher order Bragg condition) [22, 24]. Apodization consists in forcing a suitable, spatial distribution of light intensity from the laser writing the grating. Many apodizing functions are known. Gaussian, cosine, raised cosine, sinc function are the ones most commonly used. In order to obtain an apodized $\mathrm{T}(\mathrm{z})$ profile, one uses a particular transformation [34]:

$$
\begin{array}{ll}
\text { Gaussian profile: } & T(z)=\exp \left\{-a\left[\frac{\left(z-\frac{L}{2}\right)}{L}\right]\right\}^{2} \\
\text { Sinc profile: } & \left.T(z)=\left\{\frac{\sin \left[\frac{2 \pi\left(\frac{L}{2}\right)}{L}\right]}{\frac{2 \pi\left(\frac{L}{2}\right)}{L}}\right\}^{\mathrm{n}}\right\}^{2} \\
\text { Hamming profile: } & T(z)=n\left\{\frac{1+H \cos \left[\frac{2 \pi\left(\frac{L}{2}\right)}{L}\right]}{1+H}\right\} \\
\text { Sin profile: } & T(z)=\sin ^{m}\left(\frac{\pi z}{L}\right) \\
\text { Cauchy profile: } & T(z)=\frac{1-\left[\frac{2\left(z-\frac{L}{2}\right)}{L}\right]^{2}}{1-\left[\frac{2 c\left(z-\frac{L}{2}\right)}{L}\right]^{2}},
\end{array}
$$

where $L$ is the length of the grating. Reflection characteristics for selected types of apodized variable period grating profiles are shown in Figure 1.

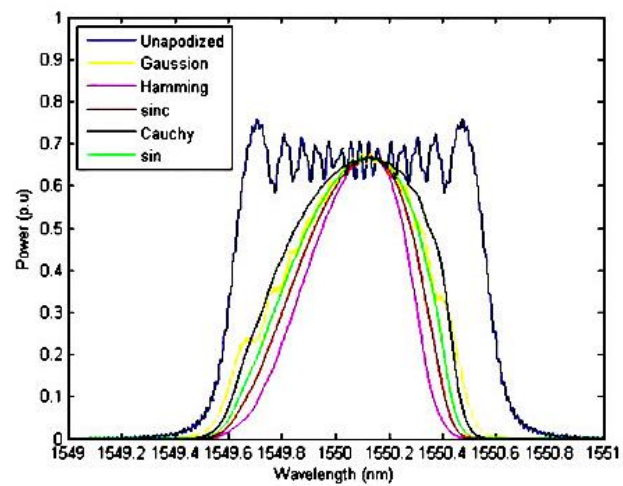

Fig. 1. Comparison of the refraction spectrum of an unapodized chirped Bragg grating with spectra of apodized gratings [34]

In Figure 1, it can be seen that the spectrum of the grating without apodization takes on a rectangular shape, which makes finding the maximum power very difficult. In the case of a grating with any apodization applied, the maximum of the spectrum can be easily determined.

\section{Uniform Bragg gratings}

Uniform Bragg gratings (gratings with a constant period and amplitude) are the simplest and most common gratings. The scheme of such grating is shown in Figure 2. It can be seen that the plane of the grating is perpendicular to the axis of the optical fiber. The light (corresponding to Bragg wavelength) is partially 
reflected at each grating period, forming a beam reflected in the opposite direction to the introduced light.

These gratings are most often produced using the phase mask method, featuring high repeatability.

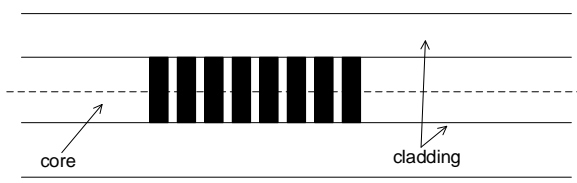

Fig. 2. Scheme of a uniform Bragg grating structure
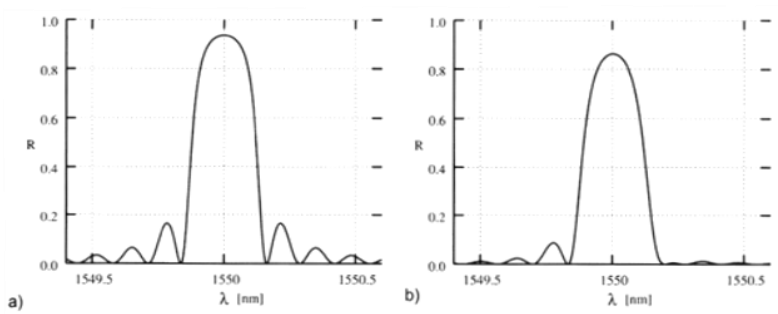

Fig. 3. Power reflection spectrum for a $6 \mathrm{~mm}$ grating: a) no apodization, b) with apodization [13]

In Figure 3, it can be observed that apodization has reduced the reflectivity by a small extent, but for that it has minimized the so-called sidebands resulting from multiple reflections from the opposite ends of the grating, which in selected applications turns out to be more important than the reduced reflectivity. The uniform Bragg gratings have found applications in optical telecommunications (dispersion compensation, optical filtering), measurement (especially strain sensors, where the whole spectrum (without sidebands) contains information about the strain distribution [2, 33]), as well as shock wave transducers [27].

\section{Chirped Bragg gratings}

Non uniform or chirped gratings feature a variable period along the axis of the optical fiber. Waves with shorter lengths are reflected in the segments of the grating where the period is smaller, while longer waves are reflected in segments with larger periods (in accordance with the Bragg's law).

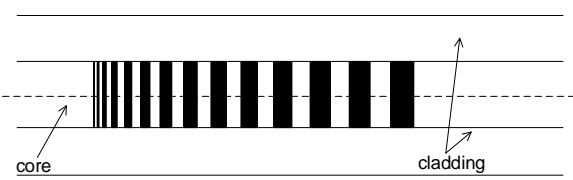

Fig. 4. Scheme of the chirped Bragg grating structure
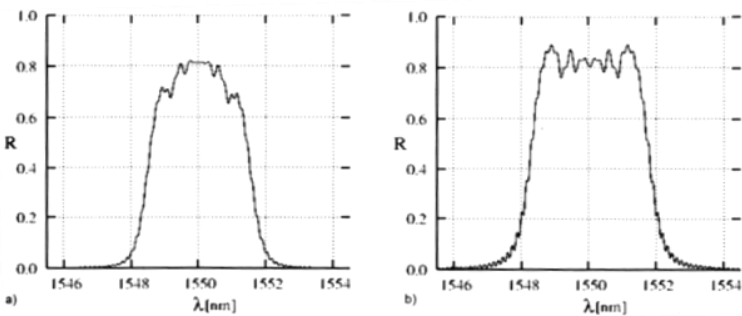

Fig. 5. Power reflection spectrum for a grating: a) with apodization, b) without apodization [13]

The resulting spectrum of a chirped Bragg grating is closer to a rectangular one for a grating without apodization than for a grating with apodization (as shown in Figure 5). Apodized chirped Bragg gratings are widely used in telecommunications and sensor technology, i.e. in spectrum analyzers [30], chromatic dispersion compensators, where apodization has a positive effect on ripples in group delay response $[1,8,16]$, linear edge filters [4].

\section{Long period gratings}

Long Period Bragg gratings (LPG) feature only transmissive properties, i.e. coupling of core modes with cladding modes [17] Because of this, LPGs do not have a reflection spectrum, therefore the transmission spectrum is shown in Figure 7. In the case of LPGs the period is much longer, compared with the other types of FBGs - for the grating in Figure 6, numerically calculated using the OptiGrating environment, the period is $150 \mu \mathrm{m}$.

Based on Figure 7 , it can be noted that the grating with apodization features less sidebands, but low dynamic range of peaks (dips). If it is necessary to obtain a higher dynamic range of peaks, similar to an unapodized grating, another " $a$ " factor should be used but the increase of index modulation changes can be a better concept. The full width at half maximum (FWHM) is much larger for the apodized grating. In the transmission spectrum of both gratings, further resonance peaks can be seen, which correspond to the subsequent mode couplings of the core mode with the modes in the fiber cladding. In reference [28] it was shown that apodization in the case of LPG makes the most sense for spectral measurements in the range (of spectrum changes) corresponding to higher cladding modes, because there is the greatest noise reduction there, and the disadvantage of apodizing is the decrease in the attenuation of waves with resonance wavelengths.

LPGs are used in sensors of non electrical quantities (strain, temperature, bending) [11], where changes in the wavelengths, at which the power minimum occurs, are measured, as well as in ultrafast optical signal processing [3].

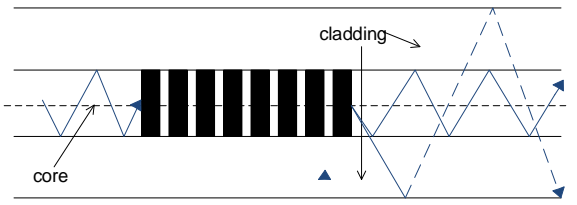

Fig. 6. Scheme of the structure and the method of coupling of the LPG modes
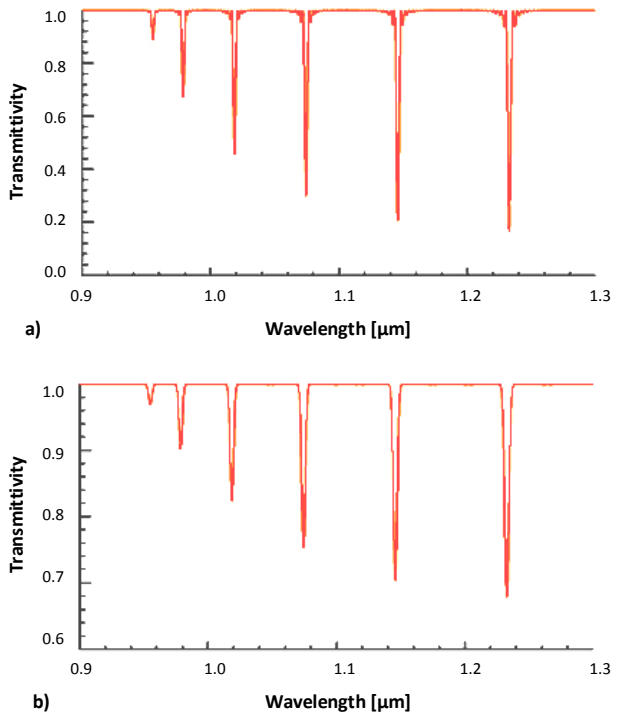

Fig. 7. Transmittivity as a function of wavelength for an LPG: a) without apodization, $b$ ) with the Gaussian apodization profile and the coefficient $a=0.5$

\section{Blazed Bragg gratings}

Blazed Bragg gratings feature an angle between the longitudinal axis of the fiber and the planes of the grating of less than $90^{\circ}$. The light introduced into the core undergoes partial reflection to the outside of the fiber, which results in the passage of a relatively small amount of light through all planes of the grating. 
In the Divison of Optoelectronics and Teleinformatic Networks of the Institute of Electronics and Information Technology of the Lublin University of Technology many types of apodized Bragg gratings are being produced - figure 9 shows the spectrum of a chirped grating with a blaze angle of $0^{\circ}$, and figure 10 - the spectrum of a chirped grating with a blaze angle of $2.5^{\circ}$. Apodization was imposed by the excimer laser beam distribution (it is approximately a Gaussian profile), and the beam distribution profile is measured using a beam profiler with a BC 106 VIS camera.

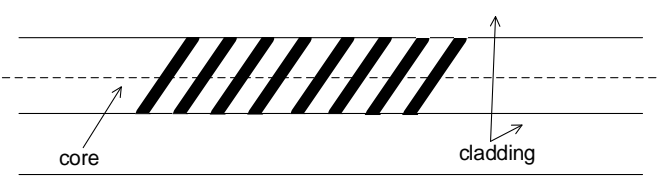

Fig. 8. Scheme of the structure of a blazed Bragg grating

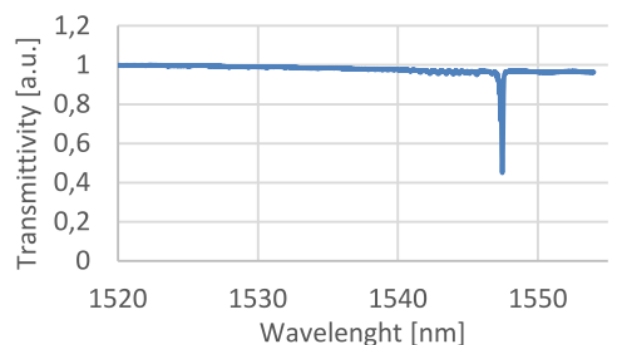

Fig. 9. Transmittivity as a function of wavelength for a $0.1 \mathrm{~nm} / \mathrm{cm}$ chirp grating and $0^{\circ}$ write angle

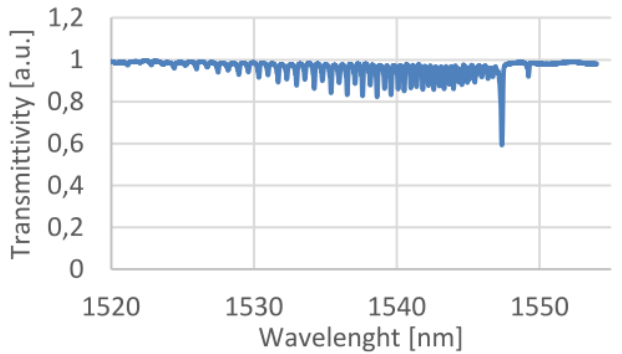

Fig. 10. Transmittivity as a function of wavelength for a $0.1 \mathrm{~nm} / \mathrm{cm}$ chirp grating and $2.5^{\circ}$ write angle

Based on the figures above, it can be seen that in the second case, the transmission of the deepest dip is higher than in the first case, and for the smaller wavelengths there are numerous peaks with transmittivity close to twice the transmittivity of the main dip.

Blazed Bragg gratings are used to build spectrometers, erbium doped fiber amplifiers (EDFA) [14]. Bragg gratings are also known to be used for bending sensors [5], spectrum analyzers [30], polarization discriminators [18].

\section{Methods of producing apodized Bragg gratings}

Apodized fiber optic Bragg gratings are produced using the phase mask method, multiple printing of in-fiber gratings, the moving fiber/phase mask technique, the symmetric stretch apodization method, using phase mask with variable diffraction efficiency method. Furthermore point-by-point method [32] using a $\mathrm{CO}_{2}$ laser [9] or a UV laser [12] is used to LOG inscription.

The phase mask method is the simplest and most effective technique for producing gratings. It consists in directing a beam of UV light onto a diffraction structure made of quartz glass. For a grating with a particular period $\Lambda$, a phase mask with a period of $2 \Lambda$ is required. In order to move the beam of light on the surface of the optical fiber, precise positioning mechanisms are created. This method works very well in the production of uniform and blazed gratings. The selected apodization profile is created by using a properly designed and manufactured lens that focuses the light beam on the fiber [25].
The multiple printing of in-fiber gratings (MPF) consists in writing short $(4 \mathrm{~mm})$ gratings that overlap each other, so after each print several new grating periods are created. A pulse generating UV laser is used for this. The segment of the fiber where the grating is supposed to be inscribed is placed in a V-shaped glass groove. Precise movement the fiber forward and backward is controlled by a computer. The light source - an interferometer is in a fixed position [15].

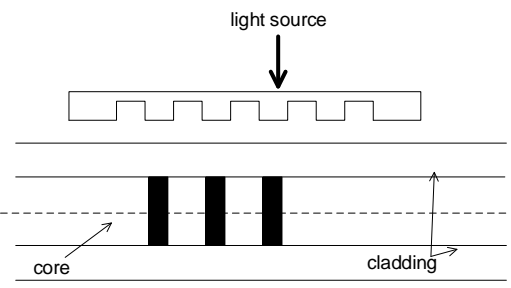

Fig. 11. Scheme of the setup for producing gratings using the phase mask method

In the moving fiber/phase mask technique (MPM), the fiber and phase mask are fixed in a holder, moved by a precision piezoelectric device. The UV beam remains stationary. During the creation of the grating, the fiber is being moved forward and backward, thus creating a "blur" effect of the grating. MPM allows to create an apodized gratings with a variable period. Figure 12 shows the scheme for writing gratings with this method.

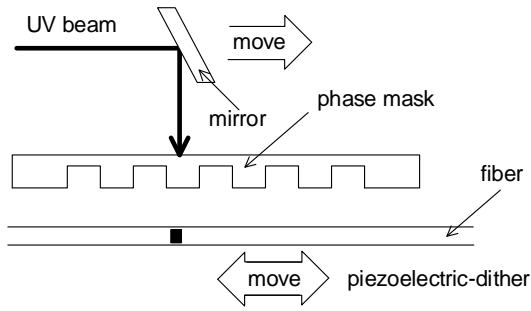

Fig. 12. Scheme of the setup for producing gratings using the MPM method

Similar to MPM apodization technique, where phase mask is dithered instead of optical fiber is presented in [20].

The symmetric stretch apodization method (SAM) is a combination of the MPF and MPM methods, so strict synchronization of the fiber and UV beam positioning systems is required. This allows the writing of two gratings in the same place, with the correct phase relation between them. First, the grating is written on an non-deformed fiber and then on a deformed one. The stretching and loosening of the fiber is carried out using a piezoelectric transducers [15]. Figure 13 shows the SAM scheme using a phase mask, which can be replaced with an interferometer.

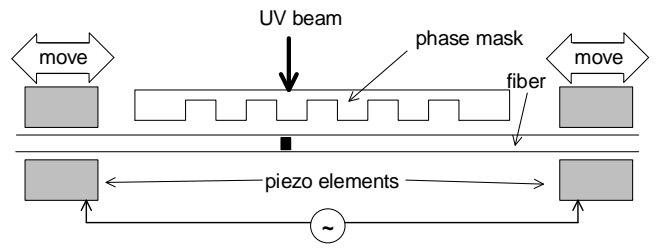

Fig. 13. Scheme of the setup for producing gratings using the SAM method

The phase mask with variable diffraction efficiency is the most reproducibility method. There is constant effective refractive index along the whole grating, so short-wavelength side broadening of spectral characteristic is avoiding in this method. The change of duty cycle and groove depth causes variable diffraction efficiency of the phase mask. The coherent UV laser beam lights up the phase mask and the interference pattern is writing in the fiber core. The technique is working in the case of sources with low coherence, because there is a small distance between the optical fiber and the phase mask [23]. 


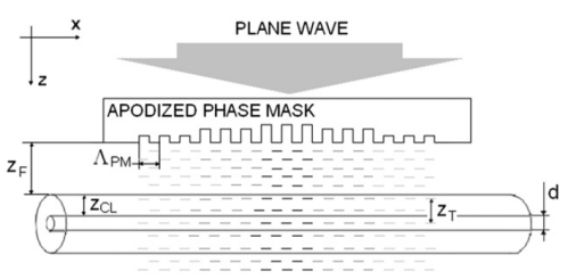

Fig. 14. Scheme of the setup for producing gratings using the phase mask with variable diffraction efficiency, where where: $z_{F}$ is the distance between phase mask and the optical fiber, $z_{T}$ is the Talbot distance [23]

\section{Conclusions}

The apodization minimizes the side bands of the transmission spectrum for all types of gratings described above. An undeniable disadvantage of apodization is the reduction in the reflectivity of the transmission spectrum, whereas in the majority of applications of Bragg gratings, it is more important to minimize the side bands than to obtain the highest possible main peak, which is still high even for apodized gratings. There are several methods for producing apodized Bragg gratings that are constantly being improved due to the increasingly precise devices used to produce the designed gratings. The use of a phase mask considerably speeds up the process of formation of periodic structures and contributes to their mass production. Nevertheless, for the production of some types of gratings, it is more convenient to use an interferometer (interference method).

\section{Literature}

[1] Aladadi Y.T., Abas A.F., Alresheedi M.T.: Performance Optimization of an Apodized-Chirped Fiber Bragg Gratings Based Chromatic Dispersion Compensator. IEEE ICTON 2016, 1-5.

[2] Ashik T.J. et al.: Analysis of simultaneous measurement of temperature and strain using different combinations of FBG. AIP Conf. Proc. 1849, 2017, 020031-1-020031-8.

[3] Ashrafi R., Asghari M.H., Azana J.: Ultrafast Optical Arbitrary-Order Differentiators Based on Apodized Long-Period Gratings. IEEE Photonics Journal, vol. 3, no 3, 2011, 353-364.

[4] Bandyopadhyay S. et al.: Empirical Relations for Design of Linear Edge Filter Using Apodized Linearly Chirped Fiber Bragg Grating. Journal of Lightwave Technology, vol. 26, no. 24, 2008, 3853-3859.

[5] Beak S., Jeong Y., Lee B.: Characteristics of short-period blazed fiber Bragg gratings for use as macro-bending sensors. Optical Society of America, vol. 41 , no $4,2002,631-636$

[6] Campbell R.J., Kashyap R.: Optically written Bragg gratings in photosensitive fibre. IEE Colloquium on Non-Linear Effects in Fibre Communications, 1990 $4 / 1-4 / 3$

[7] Dziubiński G. et al.: Optymalizacja parametrów światłowodowych czujników do pomiaru temperatury. Annual Set The Environment Protection 18/2016, 309-324.

[8] Faiyaz N.M., Omi A.I., Faisal M.: Optimization of Apodization Profile of Chirped Fiber Bragg Grating for Chromatic Dispersion Comensation, Dispersion Compensation Using Chirped Apodized FBG. International Conference on Electrical Engineering and Information \& Communication Technology (ICEEICT) 2014, 1-5

[9] Gu Y., Chiang K. S., Rao Y. J.: Writing of Apodized Phase-Shifted Long-Period Fiber Gratings With a Computer-Controlled CO2 Laser. IEEE Photonics Technology Letters, vol. 21, no. 10, 2009, 657-659.

[10] Hill K.O., Fujii Y., Johanson D.C., Kawasaki B.S.: Photosensivity in optica fiber waveguides: aplication to reflection filter fabrication. Appl. Phys. Lett. 32 647, 1978, 647-649.

[11] James S.W., Tatam R.P.: Optical fibre long-period grating sensors: characteristics and application. Meas. Sci. Technol. 14, 2003, 49-61.

[12] James S.W., Topliss S.M., Tatam R.P.: Properties of Length-Apodized PhaseShifted LPGs Operating at the Phase Matching Turning Point. Journal of Lightwave Technology, vol. 30, no. 13, 2012, 2203-2209.

[13] Kaczmarek Z.: Światłowodowe czujniki i przetworniki pomiarowe. PAK, Warszawa 2006.

[14] Kashyap R., Wyatt R., Campbell R.J.: Wideband gain flattened erbium fibre amplifier using a photosensitive fibre blazed grating. Electronics Letters $21 \mathrm{st}$ vol. 29 , no. $2,1993,154-156$

[15] Kashyap R.: Fiber Bragg Gratings. Academic Press, 1999.

[16] Khan S.S.A., Islam M.S.: Chromatic Dispersion Compensation Using Linearly Chirped Apodized Fiber Bragg Grating. ICECE 2010, 9-12

[17] Kisała P.: Periodyczne struktury światłowodowe w optoelektronicznych czujnikach do pomiaru wybranych wielkości nieelektrycznych. Monografie Politechnika Lubelska 2012.

[18] Labidi H., Debarros C., Letteron R., Riant I.: Slanted Bragg grating with ultralow polarization dependant loss. Optical Fiber Communication Conference and Exhibit 2002, 113

[19] Lam D.K.W., Garside B.K., Hill K.O.: Dispersion cancellation using opticalfiber filters. Optical Society of America, vol. 7, no. 6, 1982, 291
[20] Markowski K., Perka A., Jędrzejewski K., Osuch T.: Custom FBGs inscription using modified phase mask method with precise micro and nano-positioning. Proc. SPIE vol. 10031, 2016, 100311H [doi: 10.1117/12.2249381].

[21] Morey W.W., Meltz G., Weiss J.M.: Separation Of Temperature And Strain Measurands In Fiber Bragg Grating Sensors. LEOS '92 Conference Proceedings IEEE Lasers and Electro-Optics Society, 1992, 454-455.

[22] Osuch T., Jaroszewicz Z.: Influence of optical fiber location behind an apodized phase mask on Bragg grating reflection efficiencies at Bragg wavelength and its harmonics. Opt. Commun. 382, 2017, 36-41.

[23] Osuch T., Jaroszewicz Z.: Numerical analysis of apodized fiber Bragg gratings formation using phase mask with variable diffraction efficiency. Optics Communications, vol. 284, 2011, 567-572.

[24] Osuch T.: Numerical analysis of harmonic components of the Bragg wavelength content in spectral responses of apodized fiber Bragg gratings written by means of phase mask with variable phase step height, J. Opt. Soc. Am. A 33 (2), 2016, $172-178$.

[25] Otto M. et al.: Flexible Manufacturing Method For Long-Period Fibre Gratings With Arbitrary Index Modulation Profiles. Fibre and Optical Passive Components, 2002, 6-11.

[26] Pastor D. et al.: Design of Apodized Linearly Chirped Fiber Gratings for Dispersion Compensation, Journal of Lightwave Technology, vol. 14, no. 11, 1996, 2581-2588.

[27] Sikora A.: Apodyzowane siatki Bragga o stałym okresie jako przetworniki odkształceń impulsowych. Analiza numeryczna. PAK, vol. 56, nr 12, 2010, 1436-1438.

[28] Stepniak P., Kisała P.: Analisys of impact long period Bragg gratings parameters on their special transmission characteristics. Proc. SPIE 10445, 2017, 104450G [doi: 10.1117/12.2280868].

[29] Theriault S. et al.: Effect of phase mask stitching errors on the spectral response of uniform and apodized fiber Bragg gratings. 8th Annual Meeting Conference Proceedings, vol. 1, 1995, 77-78.

[30] Wagner J.L. et al: Fiber Grating Optical Spectrum Analyzer Tap. Integrated Optics and Optical Fibre Communications, 11th International Conference on, and 23rd European Conference on Optical Communications, no. 448, 1997. 65-68 [doi: 10.1049/cp:19971613].

[31] Wang L. et al.: Impact of apodisation functions on group delay and reflectivity ripple of chirped fiber Bragg gratings. Optoelectronics Letters, vol. 2, no. 6 , 2006, 430-432.

[32] Williams R. et al.: Modeling of apodized point-by-point fiber-Bragg gratings. 2011 International Quantum Electronics Conference (IQEC) and Conference on Lasers and Electro-Optics (CLEO) Pacific Rim incorporating the Australasian Conference on Optics, Lasers and Spectroscopy and the Australian Conference on Optical Fibre Technology, 133-135.

[33] Wójcik W., Kisała P.: Modelowanie struktur światłowodowych siatek Bragga wykorzystywanych $w$ układach czujnikowych. PAK vol. 53, no.11, 2007, 10-14.

[34] Yu Y., Zhenhong Y.: Performance optimization of chirped fiber Bragg grating by asymmetrical apodization. Proc. of the SPIE 10250, 2017, 1025003-6.

\section{M.Sc. Lukasz Zychowicz}

e-mail:lukas.zychowicz@gmail.com

Lukasz Zychowicz is currently Ph.D. student in the Institute of Electronics and Information Technology of Lublin University of Technology (LUT). He is working as telecommunication networks designer. In 2016, he graduated from Mechatronics at LUT. His main scientific interests are apodized Bragg gratings.

\section{M.Sc. Jacek Klimek}

e-mail: j.klimek@pollub.pl

Jacek Klimek - assistant in the Electrical Engineering and Computer Science Faculty of the Lublin University of Technology, author of many publications on fiber-optic topics. His research focuses on the production and testing optical periodic structures known as Bragg gratings. Current scientific interests focus on issues related to bistable optical systems and complex periodic structures.

\section{D.Sc. Piotr Kisała}

e-mail: p.kisala@pollub.pl

Piotr Kisała is currently a professor in the Institute of Electronics and Information Technology of Lublin University of Technology (LUT), Lublin, Poland. He received the Ph.D. degree in 2009 and habilitation degree in 2013 from LUT. He is currently head of Optoelectronic \& ICT Department at LUT. His research interests include optical sensors projects, fabrication and testing as well as designing and developing of unconventional FBG sensors. He has authored over 70 journal publications and conference contributions and 2 patents.
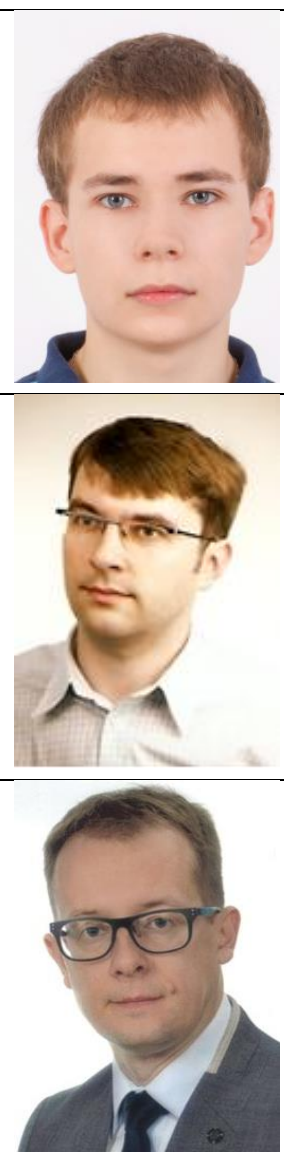